\title{
PERILAKU SANTRIWAN YANG BARU MONDOK DI PESANTREN K-K KECAMATAN SAKO TERHADAP KEJADIAN PENYAKIT KULIT SKABIES
}

\author{
Ahmad Ghiffari ${ }^{*}$, Lucille Annisa Suardin ${ }^{2}$, Raden Pamudji ${ }^{3}$, Zadi Oktariansyah ${ }^{4}$ \\ ${ }^{1}$ Departemen Parasitologi Fakultas Kedokteran Universitas Muhammadiyah Palembang \\ 16 Ulu, Kec. Seberang Ulu II, 30116, Kota Palembang, Sumatera Selatan, Indonesia \\ 2Departemen Ilmu Kulit dan Kelamin Rumah Sakit Umum Palembang BARI \\ JI. Panca Usaha No.1, 5 Ulu, Kecamatan Seberang Ulu I, 30254, Kota Palembang, Sumatera Selatan, \\ Indonesia \\ ${ }^{3}$ Departemen Ilmu Kulit dan Kelamin Fakultas Kedokteran Universitas Muhammadiyah Palembang \\ 16 Ulu, Kec. Seberang Ulu II, 30116, Kota Palembang, Sumatera Selatan, Indonesia \\ ${ }^{4}$ Program Studi Pendidikan Kedokteran Fakultas Kedokteran Universitas Muhammadiyah Palembang \\ 16 Ulu, Kec. Seberang Ulu II, 30116, Kota Palembang, Sumatera Selatan, Indonesia
}

\begin{abstract}
About 300 million scabies cases per year are reported worldwide, and in Indonesia is estimated at $3,9-9 \%$ of the population. Factors related to the risk of mite infestation include poor personal hygiene, contact with sufferers, high humidity, high occupancy density and low knowledge. These risk factors are high in the students of boarding school residents. The research activity aims to determine the risk factor and relation of scabies skin disease in boarding school K-K in Sako district of Palembang. The research design in the form of analytical observational is at 114 students, with clinical examination (cardinal sign) symptoms of scabies and microscopic and questionnaire. Results show that the subject of research affected by skabies much as $37 \%$ is dominated by the gender of males (53\%), located at the level of Tsanawiyah (63\%) at Seventh grade (40\%), has a moderate level of knowledge (49\%), has a moderate attitude level (48\%), and has a good behavioral level (52\%). Bivariate and logistics analysis of multivariate regression demonstrates the connection between scabies and the behavior of knowledgeattitudes, with the greatest influence on behavior (OR 8.24). It is advisable to improve the knowledge, attitudes especially the behaviors such as by not using personal belongings together. Counseling especially in students who are newly entered the dormitory must be encouraged, by inviting puskesmas as the form of clinic for the socialization of diseases, especially for the seventh grade of Tsanawiyah Santriwan.
\end{abstract}

Keywords: Scabies, pesantren, behavior, fresh students, counseling.

\section{BEHAVIOR OF FRESH MALE STUDENT WHO ENTER THE PESANTREN K-K KECAMATAN SAKO WITH SCABIES DISEASE}

\begin{abstract}
Abstrak
Sekitar 300 juta kasus skabies per tahunnya dilaporkan di seluruh dunia dan di Indonesia 3,9$9 \%$ penduduk. Faktor-faktor yang berhubungan dengan risiko infestasi tungau antara lain higienitas pribadi yang buruk, kontak dengan penderita, kelembapan, kepadatan hunian yang tinggi dan pengetahuan yang rendah. Faktor risiko tersebut tinggi pada santri penghuni asrama pesantren. Kegiatan penelitian bertujuan untuk menentukan faktor risiko dan hubungannya penyakit kulit kudis pada Pondok Pesantren K-K di Kecamatan Sako Kota Palembang. Penelitian dilakukan melalui metode observasi dengan menggunakan pendekatan desain potong lintang pada 114 santri dengan prosedur pemeriksaan klinis (cardinal sign) gejala skabies dan mikroskopis serta kuesioner. Hasil menunjukkan bahwa subjek penelitian yang terkena skabies sebanyak $37 \%$ didominasi oleh jenis kelamin laki-laki $(53 \%)$, berada pada tingkat tsanawiyah (63\%) kelas VII (40\%), memiliki tingkat pengetahuan sedang (49\%), tingkat
\end{abstract}


sikap sedang (48\%), tingkat perilaku baik (52\%). Analisis bivariat dan logistik regresi multivariat menunjukkan hubungan antara kejadian skabies dengan pengetahuan, sikap, perilaku, dengan pengaruh paling besar pada perilaku (OR 8,24). Disarankan untuk tidak menggunakan barang pribadi secara bersama. Penyuluhan terutama pada santri yang baru masuk asrama harus lebih digalakkan dengan melibatkan pihak puskesmas untuk sosialisasi penyakit terutama bagi santriwan kelas VII tsanawiyah.

Kata Kunci: Skabies, pesantren, perilaku, santri baru, penyuluhan.

*Alamat korespondensi penulis pertama: email: ahmad_ghiffari@um-palembang.ac.id; Telp: (0711) 520045

\section{PENDAHULUAN}

Diperkirakan sekitar 300 juta kasus skabies per tahunnya di seluruh dunia. Skabies merupakan masalah kesehatan yang cukup besar di banyak negara berkembang. Tahun 2017 World Health Organization (WHO) telah menyatakan bahwa skabies termasuk Neglected Tropical Disease (NTD) atau Penyakit Tropis yang Terabaikan. ${ }^{1}$ Peningkatan kasus infestasi skabies dilaporkan meningkat di negara maju seperti Norwegia. ${ }^{2}$ Prevalensi skabies di Indonesia tahun 2013 yakni 3,9-9\% sementara di Palembang sebesar $56,5 \%{ }^{3}$ Faktor-faktor yang mempengaruhi timbulnya kejadian skabies antara lain usia, jenis kelamin, higienitas pribadi yang buruk, kontak dengan penderita, kelembaban, kepadatan hunian yang tinggi dan pengetahuan yang rendah. ${ }^{4}$ Santri diketahui tinggi kasus skabies disebabkan faktor risiko yang banyak terdapat pada kondisi hunian pesantren.

Masalah penyakit kulit yang berulang mengganggu kualitas hidup dan akademik santri di pesantren. ${ }^{5}$ Pondok Pesantren K-K terletak di Kecamatan Sako Kota Palembang, memiliki santri tsanawiyah dan aliyah sejumlah 131 santri yang merupakan sebagian besar anak yatim dan piatu serta tinggal di asrama pesantren. Asrama pesantren terdiri dari dua gedung dan enam kamar mandi, dengan masing-masing tempat dihuni cukup padat oleh 6-12 santri. Kondisi asrama memiliki sanitasi cukup bersih, tetapi terdapat kebiasaan santri untuk saling meminjam alat pribadi seperti handuk, seprei, bantal dan pakaian dengan alasan rasa senasib sepenanggungan. Halhal tersebut memungkinkan penularan penyakit kulit dapat berlangsung. ${ }^{6}$ Fasilitas kesehatan sekitar pesantren telah berupaya untuk mengobati namun keluhan kembali berulang. Kemungkinan penyebab penyakit masih terjadi adalah disebabkan faktor dari karakteristik santri dan pengetahuan, sikap, perilaku santri terkait dengan skabies. Perlu dikaji faktor-faktor risiko dan seberapa besar pengaruhnya terhadap risiko kejadian penyakit kulit skabies di Pondok Pesantren $\mathrm{K}-\mathrm{K}$ Palembang sehingga dapat diambil tindakan penanganan yang tepat.

\section{METODE DAN BAHAN}

Subjek adalah 114 santri yang terdiri dari 59 santriwan dan 55 santriwati. Kegiatan dimulai pada tanggal 20 November sampai tanggal 1 Desember 2019. Desain penelitian merupakan observasional analitik dengan rancangan potong lintang. Hasil dianalisis secara statistik menggunakan analisis bivariat, dan analisis logistik regresi multivariat.

$$
n=\frac{Z_{1-\alpha / 2} \sqrt{2 P(1-P)}+Z_{1-\beta / 2} \sqrt{P_{1}\left(1-P_{1}\right)+P_{2}\left(1-P_{2}\right)}}{(P 1-P 2)^{2}}
$$

Besar sampel minimal menggunakan rumus proporsi dua arah, level signifikansi $5 \%$, prevalensi sebelumnya $(0,596)$ dan prevalensi effect size $30 \%(0,896)$. Besar sampel minimal adalah 32 (dikali $2=64$ ). Teknik total sampling dipilih karena semua sampel menjadi subjek penelitian. Bahan yang digunakan adalah kerokan kulit santri yang sesuai kriteria inklusi dan eksklusi. Alat dan bahan yang digunakan adalah Kalium Hidroksida $(\mathrm{KOH}) 10 \%$, skalpel, 
gelas objek, sarung tangan dan mikroskop (Olympus ${ }^{\circledR}$ ).

Metode yang dikerjakan adalah pemeriksaan (fisik dan mikroskopis) dan pembagian kuesioner. Mikroskop menggunakan pembesaran $4 \times 10$ pada bahan kerokan kulit yang telah ditetesi $\mathrm{KOH}$. Kerokan kulit yang menjadi habitat tungau dilisiskan sesaat sebelum pemeriksaan sehingga tungau terlihat menggunakan mikroskop pembesaran sedang. Pembagian kuesioner berupa pengumpulan data karakteristik responden dan pengetahuan, sikap, perilaku responden mengenai skabies.

Pemeriksaan untuk mendiagnosis skabies adalah dengan terdapatnya tanda kardinal. Tanda kardinal adalah riwayat gatal pada malam hari (pruritus nokturnal), riwayat gatal yang sama pada sekolompok manusia, adanya terowongan pada tempat predileksi (berbentuk lurus/bengkok berwarna putih/abu-abu) dan ditemukan tungau secara mikroskopis. Dasar penegakkan diagnosis skabies adalah ada minimal 2 dari 4 tanda kardinal.
Analisis statistik secara bivariat dan multivariat. Analisis bivariat menggunakan chi-square yaitu untuk menguji hubungan variabel bebas dan variabel terikat. Signifikansi hubungan ditandai dengan " $p$ ", dimana nilai yang kurang dari 0,05 berarti berhubungan. Analisis multivariat menggunakan logistik regresi, untuk menguji variabel bebas yang paling dominan dan paling berpengaruh terhadap variabel terikat. Signifikansi hubungan ditandai dengan "Sig.", dimana nilai yang kurang dari 0,05 berarti berhubungan. Kekuatan hubungan ditandai dengan "Exp(B)", dimana nilai 9,4 berarti berisiko 9,4 kali lebih besar dari pada faktor yang lain.

\section{HASIL}

Sekitar $35,7 \%$ santri terdiagnosis skabies berdasarkan pemeriksaan klinis. Pemeriksaan mikrsokopis tidak ditemukan tungau, maka penegakkan diagnosis didasarkan hasil pemeriksaan fisik responden. Data detil kasus terdapat pada Tabel 1.

Tabel 1. Frekuensi kejadian skabies berdasarkan pemeriksaan fisik

\begin{tabular}{lcc}
\hline \multicolumn{1}{c}{ Variabel } & Jumlah & Persentase (\%) \\
\hline Skabies & 41 & 35 \\
Tidak Skabies & 74 & 64 \\
\hline Total & 115 & 100 \\
\hline
\end{tabular}

Analisis bivariat hubungan kejadian skabies dengan faktor risiko karakteristik responden (pada Tabel 2, 3 dan 4) dan pengetahuan-sikap-perilaku (pada Tabel 6, 7 dan 8) menunjukkan hubungan bermakna kecuali pada faktor umur (lihat Tabel 5).

Tabel 2. Hubungan antara jenis kelamin dengan kejadian skabies

\begin{tabular}{lccc}
\hline \multicolumn{1}{c}{ Variabel } & LK & PR & Nilai $p$ \\
\hline Skabies & 33 & 8 & $<0,001$ \\
Tidak Skabies & 28 & 46 & \\
\hline Total & 61 & 54 & \\
\hline Keterangan: $L K=$ Laki-laki, $P R=$ Perempuan
\end{tabular}


Tabel 3. Hubungan antara pendidikan dengan kejadian skabies

\begin{tabular}{lccc}
\hline \multicolumn{1}{c}{ Variabel } & TS & AL & Nilai $p$ \\
\hline Skabies & 32 & 9 & 0,016 \\
Tidak Skabies & 41 & 33 & \\
\hline Total & 73 & 42 & \\
\hline \multicolumn{4}{r}{ Keterangan: $T S=$ Tsanawiyah, $A L=$ Aliyah }
\end{tabular}

Tabel 4. Hubungan antara kelas dengan kejadian skabies

\begin{tabular}{|c|c|c|c|c|c|c|c|}
\hline V & 7 & 8 & 9 & 10 & 11 & 12 & Nilai $p$ \\
\hline SP & 25 & 6 & 1 & 8 & 0 & 1 & 0,01 \\
\hline SN & 21 & 14 & 6 & 19 & 11 & 13 & \\
\hline Total & 46 & 20 & 7 & 27 & 11 & 14 & \\
\hline
\end{tabular}

Tabel 5. Hubungan antara umur dengan kejadian skabies $(p=0,77)$

\begin{tabular}{crrrrrrrr}
\hline $\mathrm{V}$ & 11 & 12 & 13 & 14 & 15 & 16 & 17 & 18 \\
\hline $\mathrm{SP}$ & 3 & 19 & 5 & 2 & 5 & 6 & 0 & 1 \\
$\mathrm{SN}$ & 2 & 18 & 13 & 5 & 10 & 11 & 12 & 3 \\
\hline Total & 5 & 37 & 18 & 7 & 15 & 17 & 12 & 4 \\
\hline \multicolumn{7}{c}{ Keterangan: $V=$ variabel, $S P=$ Skabies Positif, SN $=$ Skabies Negatif }
\end{tabular}

Tabel 6. Hubungan antara pengetahuan dengan kejadian skabies

\begin{tabular}{lrrrr}
\hline \multicolumn{1}{c}{ Variabel } & KG & SG & BK & Nilai $p$ \\
\hline Skabies & 25 & 12 & 4 & $<0,001$ \\
Tidak Skabies & 17 & 45 & 12 & \\
\hline Total & 42 & 57 & 16 & \\
\hline \multicolumn{5}{c}{ Keterangan: $K G=$ Kurang, SG $=$ Sedang, BK = Baik }
\end{tabular}

Tabel 7. Hubungan antara sikap dengan kejadian skabies

\begin{tabular}{|c|c|c|c|c|}
\hline Variabel & KG & SG & BK & Nilai $p$ \\
\hline Skabies & 3 & 29 & 9 & $<0,001$ \\
\hline Tidak Skabies & 1 & 27 & 46 & \\
\hline Total & 4 & 56 & 55 & \\
\hline
\end{tabular}

Tabel 8. Hubungan antara perilaku dengan kejadian skabies

\begin{tabular}{lrrrrr}
\hline \multicolumn{1}{c}{ Variabel } & KG & SG & BK & Nilai $p$ \\
\hline Skabies & 26 & 9 & 6 & $<0,001$ \\
Tidak Skabies & 2 & 18 & 54 & \\
\hline Total & 28 & 27 & 60 & \\
\hline \multicolumn{5}{c}{ Keterangan $: K G=$ Kurang,SG $=$ Sedang, BK = Baik }
\end{tabular}


Analisis multivariat hubungan kejadian skabies dengan faktor risiko pengetahuan, sikap, perilaku (Tabel 9) menunjukkan hubungan bermakna, dengan faktor yang terbesar adalah perilaku.

Tabel 9. Hasil uji regresi logistik

\begin{tabular}{lcccc}
\hline \multicolumn{1}{c}{ Variabel } & B & Df & Sig. & Exp(B) \\
\hline Sikap & 1,157 & 1 & 0,025 & 3,182 \\
Perilaku & 2,109 & 1 & 0,000 & 8,240 \\
Constant & $-3,504$ & 1 & 0,000 & 0,030 \\
\hline \multicolumn{2}{l}{ Keterangan: $B=$ Logaritma Natural } & & &
\end{tabular}

\section{BAHASAN}

Santri yang didiagnosis skabies cukup banyak yakni sebanyak 41 orang $(35,7 \%)$. Hal ini sejalan hasil di Pondok Pesantren Darul Muklisin Kota Kendari yang mendapatkan sebanyak 38\%.7 Juga hampir sama dengan hasil jumlah santri yang mengalami skabies di Pondok Pesantren Darrurahmah Gunung Putri Bogor sebanyak $47 \% .^{8}$ Wabah skabies sering dijumpai di lingkungan padat penghuni dengan kontak kulit yang erat dan lama seperti di tempat penitipan anak, panti asuhan, tempat perawatan orang usia lanjut, penjara, pengungsian dan pesantren bahkan di rumah sakit. $^{9}$

Median usia subjek adalah 13 tahun. Karakteristik ini sama dengan usia subjek sebuah penelitian di Kendari, Sulawesi Tenggara yang dilakukan pada tahun 2016. ${ }^{10}$ Subjek penelitian ini didominasi oleh jenis kelamin laki-laki, berada pada tingkat tsanawiyah, kelas VII, memiliki tingkat pengetahuan sedang, tingkat sikap sedang, tingkat perilaku baik dan tidak didagnosis skabies. Tingkat pengetahuan tersebut sejalan dengan sebuah penelitian di Banyumas, Jawa Tengah pada tahun $2017^{11}$ dengan tingkat pengetahuan yang sedang (74\%). Namun tingkat sikap dalam penelitian ini tidak sejalan dimana subjek penelitiannya memiliki tingkat sikap yang baik. ${ }^{12}$ Tingkat perilaku dalam penelitian ini sejalan dengan sebuah penelitian di Yogyakarta pada tahun 2019. Penelitian dengan desain cross sectional yang melibatkan 80 santri pondok pesantren tersebut menunjukkan bahwa $31 \%$ subjek memiliki tingkat perilaku yang cukup atau sedang. ${ }^{13}$
Hasil analisis menyatakan terdapat hubungan antara pengetahuan dengan timbulnya kejadian skabies di Pesantren K$\mathrm{K}$ Palembang. Hal ini sejalan dengan penelitian di Pesantren Daarul Qur'an Surakarta dengan $p=0,024^{12}$ dan pesantren Qotrun Nada kota Depok hasil $p=0,009^{14}$ sehingga dapat disimpulkan bahwa santri yang memiliki pengetahuan kurang tentang skabies lebih rentan menderita skabies.

Terdapat hasil yang menyatakan hubungan antara sikap dengan timbulnya kejadian skabies. Hasil yang sama juga di Pesantren Qotrun Nada Depok dan Pesantren Daarul Qur'an Surakarta dengan nilai $p=0,029$ dan $p=0,017.4,12$ Disimpulkan santri yang tidak menderita skabies memiliki sikap lebih baik.

Terdapat hubungan yang signifikan antara perilaku santri dengan timbulnya kejadian skabies. Hal ini sejalan dengan penelitian yang dilakukan di pesantren di Jakarta Timur dengan nilai $p=0,008 .{ }^{15}$ Hasil serupa juga pada pesantren di Kabupaten Ogan llir dengan signifikansi $p$ value $=0,004 .{ }^{16}$ Dapat disimpulkan bahwa santri dengan perilaku kurang akan berisiko tinggi terkena penyakit skabies.

Diketahui dari analisis bahwa karakteristik jenis kelamin, pendidikan dan kelas berhubungan dengan diagnosis skabies dengan nilai $p$ berturut-turut 0,001 ; 0,$016 ; 0,01$. Jenis kelamin perempuan lebih sedikit mengalami skabies, pendidikan dan kelas yang lebih tinggi lebih sedikit terjangkit karena pengetahuan yang lebih tinggi. Hal ini sejalan dengan hasil di dua pesantren yaitu Pesantren Raudhatul Ulum, Indralaya dan Pesantren Mustaqimus Sunnah Palembang. ${ }^{3,17}$ Hanya karakteristik usia diketahui tidak memiliki hubungan 
dengan kejadian skabies dengan $p$ value $=$ 0,77 . Hal ini menunjukkan bahwa skabies dapat terjadi pada usia berapapun di lokasi penelitian.

Analisis multivariat menunjukkan bahwa santri dengan sikap yang kurang berisiko 3,1 kali terhadap kejadian skabies. Sementara perilaku yang kurang berisiko 8,2 kali terhadap kejadian skabies. Hasil ini sejalan dengan di pesantren daerah Purworejo Jawa Tengah sebesar 9,4 kali dan menjadikan perilaku sebagai faktor yang paling berisiko terhadap kejadian skabies. ${ }^{18}$ Perilaku yang kurang dapat memberikan peluang pada para santri untuk tertular tungau Sarcoptes scabiei. ${ }^{4}$

\section{KESIMPULAN}

Prevalensi skabies di pesantren $\mathrm{K}-\mathrm{K}$ Palembang 2019 sebesar 35,7\%. Faktor risiko yang berhubungan karakteristik santri adalah jenis kelamin laki-laki, kelas VII dan pendidikan tsanawiyah. Faktor risiko lainnya adalah pengetahuan, sikap dan perilaku. Faktor risiko terbesar adalah perilaku yang kurang higienis dengan risiko sebesar 9,4 kali.

\section{SARAN}

Disarankan untuk tidak menggunakan barang pribadi secara bersama-sama dan mengaktifkan kembali fungsi Pos Kesehatan Pesantren. Penyuluhan terutama pada santri yang baru masuk asrama dengan mengundang Puskesmas Sematang Borang untuk sosialisasi penyakit terutama bagi santriwan kelas VII (tsanawiyah).

\section{KONTRIBUSI PENULIS}

Kontribusi penulis pada artikel ini yaitu, AG sebagai kontributor utama berkontribusi terhadap pengumpulan data, pembuatan pendahuluan, pembahasan, penarikan kesimpulan, menyiapkan referensi/daftar pustaka dan perbaikan bahasa di dalam artikel. LAS sebagai kontributor utama berkontribusi dalam penentuan ide penulisan, pengumpulan data dan analisis data. RP sebagai kontributor anggota berkontribusi dalam penentuan ide penulisan dan analisis data. ZO sebagai kontributor anggota berkontribusi dalam pengumpulan data, analisis data dan pembuatan pendahuluan.

\section{UCAPAN TERIMA KASIH}

Terimakasih kepada pengurus Pesantren K-K dan Pemerintah Kota Puskesmas Sematang Borang atas izin untuk melakukan kegiatan di ponpes. Juga kepada Pihak Rektorat/Dekanat atas hibah pengabdian kepada masyarakat.

\section{DAFTAR PUSTAKA}

1. Yeoh DK, Anderson A, Cleland G, Bowen AC. Are scabies and impetigo "normalised"? A cross-sectional comparative study of hospitalised children in northern Australia assessing clinical recognition and treatment of skin infections. PLoS Negl Trop Dis. 2017;11(7):1-16. doi:10.1371/journal.pntd.0005726

2. Amato E, Dansie LS, Grøneng GM, et al. Increase of scabies infestations, Norway, 2006 to 2018. Eurosurveillance. $\quad 2019 ; 24(23): 1-5$. doi:10.2807/15607917.ES.2019.24.23.190020

3. Arisandi $Y$, Anwar C, Salni S, Purnama DH, Novrikasari N, Ghiffari A. The Dominant Factors of Scabies Incidence in Two Islamic Boarding School Students, South Sumatera, Indonesia. E3S Web Conf. 2018;68:1-6.

doi:10.1051/e3sconf/20186801018

4. Ibadurrahmi $\mathrm{H}$, Veronica $\mathrm{S}$, Nugrohowati N. Faktor-Faktor Yang Berpengaruh Terhadap Kejadian Penyakit Skabies Pada Santri Di Pondok Pesantren Qotrun Nada Cipayung Depok Februari Tahun 2016. J Profesi Med J Kedokt dan Kesehat. 2017;10(1):33-45. doi:10.33533/jpm.v10i1.12

5. Merti LGIA. Hubungan Skabies dengan Prestasi Belajar pada Santri Pondok Pesantren di Bandar Lampung (Skripsi). Progr Stud Pendidik Dr Fak Kedokt Univ Lampung. 2017. doi:10.1017/CBO9781107415324.00 4 
6. Salah Hegab D, Mahfouz Kato A, Ali Kabbash I, Maged Dabish G. Scabies among primary schoolchildren in Egypt: Sociomedical environmental study in Kafr El-Sheikh administrative area. Clin Cosmet Investig Dermatol. 2015;8:105-111.

doi:10.2147/CCID.S78287

7. Ridwan ARR, Sahrudin S, Ibrahim K. Hubungan pengetahuan, personal hygiene, dan kepadatan hunian dengan gejala penyakit skabies pada santri di pondok pesantren darul muklisin kota kendari 2017. Jimkesmas. 2017;2(6):1-8.

8. Nisa FR, Rahmalia D. Faktor-faktor yang Berhubungan dengan Kejadian Skabies pada Santri Putra di Pondok Pesantren Darurrahmah Gunung Putri Bogor. JUKMAS. 2019;3(1):1623.

9. Sungkar S. Skabies: Etiologi, Patogenesis, Pengobatan, Pemberantasan Dan Pencegahan. Badan Penerbit Fakultas Kedokteran Indonesia; 2016.

10. Daulian F, Bahar $H$, Rezal F. Peningkatan Pengetahuan, Sikap dan Tindakan Santri Melalui Metode Diskusi Kelompok Tentang Penyakit Skabies di Pondok Pesanten Al Wahidah Kendari Tahun 2016. JIMkesmas. 2016;1(3):863-875.

11. Pratama TS, Septianawati P, Pratiwi $\mathrm{H}$. Pengetahuan, sikap, kebersihan personal dan kebiasaan pada santri penderita penyakit skabies di pondok pesantren. MEDISAINS. 2017;15(3):173-178.

doi:10.30595/medisains.v15i3.2082

12. Aulia AA, Mulianto $\mathrm{N}$, Widhiati $\mathrm{S}$. Hubungan antara Perilaku Hidup Sehat (Pengetahuan, Sikap , dan Tindakan) dengan Kejadian Skabies di Pondok Pesantren Daarul Qur'an Surakarta. Nexus Kedokt Komunitas. 2017;6(1):79-89.

13. Zarkasi R. Hubungan antara Perilaku Hidup Bersih Sehat dan Tingkat Pendidikan dengan Kejadian Skabies di Pesantren Nurul Ummah Kotagede Yogyakarta (Skripsi). 2019.
14. Naftassa Z, Putri TR. Hubungan Jenis Kelamin, Tingkat Pendidikan Dan Pengetahuan Terhadap Kejadian Skabies Pada Santri Pondok Pesantren Qotrun Nada Kota Depok. Biomedika. 2018;10(2):115119.

doi:10.23917/biomedika.v10i2.7022

15. Ratnasari AF, Sungkar S. Prevalensi Skabies dan Faktor-faktor yang Berhubungan di Pesantren X, Jakarta Timur. eJKI. 2014;2(1):7-12. doi:10.23886/ejki.2.3177.

16. Putri SGAD, Ghiffari A, Anwar C, Sitorus RJ. The Dominant Factors of High Scabies Incidence in Indralaya Islamic Boarding School Students South Sumatera, Indonesia. Maj Kedokt Sriwij. 2019;4(51):186-192.

17. Argentina F, Harahap DH, Lusiana E. Risk Factors of Scabies In Students Of Aulia Cendikia Islamic Boarding School, Palembang. JKK. 2019;6(3):96-99.

18. Intiaringtyas $\mathrm{S}$, Mulyaningsih $\mathrm{B}$, Umniyati SR. Faktor Risiko Penularan Penyakit Skabies pada Santri di Pondok Pesantren An Nawawi Berjan Kecamatan Gebang Kabupaten Purworejo Jawa Tengah. Balaba J Litbang Pengendali Penyakit Bersumber Binatang Banjarnegara. 2019:83-90. doi:10.22435/blb.v15i1.1784 